\title{
UM BALANÇO DO NÚCLEO DE ESTUDOS DA RELIGIÃO, CULTURAE SOCIEDADE NO PROGRAMA DE PÓS-GRADUAÇÃO EM CIÊNCIA DA RELIGIÃO DA UNIVERSIDADE FEDERAL DE JUIZ DE FORA: A RELAÇÃO ENTRE CIÊNCIAS SOCIAIS E CIÊNCIAS DA RELIGIÃO
}

\author{
Marcelo Ayres Camurça ${ }^{1}$
}

\begin{abstract}
Resumo: $\mathrm{O}$ artigo visa apresentar um balanço das atividades do Núcleo de Estudos de Religião, Cultura e Sociedade da Universidade Federal de Juiz de Fora (UFJF), relacionando-o com a Área de Concentração "Ciências Sociais da Religião" do Programa de Pós-Graduação em Ciência da Religião (PPCIR) em que ele está inserido. Procura examinar as mudanças porque passou a Área e seu núcleo de pesquisa - na estrutura, no currículo e nas linhas de pesquisa em direção a sua configuração atual, à luz das tendências e debates que envolveram o campo de estudos da Sociologia e Antropologia voltadas para o fenômeno religioso no país na sua relação com o campo interdisciplinar das Ciências da Religião.
\end{abstract}

Palavras-chave: Pesquisa, Ciências da Religião, Sociologia da Religião, Antropologia da Religião, campo religioso brasileiro.

Abstract: This article will summarize the activities of the Center for Study on Religion, Culture and Society at the Federal University of Juiz de Fora (UFJF) and its connection with the Social Sciences of Religion area of concentration, which is part of the postgraduate program in Science of Religion (PPCIR). It will examine the changes that occurred in the area of concentration and in the research center - changes in structure, curriculum and line of research - leading to its present configuration, in light of the trends and debates involving the fields of sociology and anthropology as related to the religious phenomenon in Brazil in its relationship to the interdisciplinary field of Science of Religion.

${ }^{1}$ Professor do Programa de Pós-Graduação em Ciência da Religião da Universidade Federal de Juiz de Fora.

Debates do NER, Porto Alegre, ano 8, N. 11, P. 101-118, Jan./Jun. 2007 
Keywords: Research, Sciences of Religion, Sociology of Religion, Anthropology of Religion, Brazilian religious field.

O Grupo de Pesquisa intitulado Núcleo de Estudos da Religião, Cultura e Sociedade, do Programa de Pós-Graduação em Ciência da Religião (PPCIR) da Universidade Federal de Juiz de Fora (UFJF), possui uma singularidade em relação aos demais que figuram nesta publicação Grupos de Pesquisa na temática da religião alocados em Departamentos e Programas de Pós-Graduação de Sociologia, Antropologia e Ciências Sociais - por ser um Núcleo de pesquisa de religião que se situa num Programa de Pós-Graduaçãovoltado também exclusivamentepara a temática da religião.

Por se constituir este nosso Programa de Pós-Graduação de um caráter multidisciplinarenvolvendo três áreas distintasdas CiênciasHumanas focadas no tema da religião, quais sejam, as Ciências Sociais, a Filosofia e a Teologia/ Estudo Comparado das Religiões,como conseqüência, o Núcleo de Pesquisa vinculado ao Programa, que foi criado inicialmente com o nome de Núcleo de Estudos e Pesquisa da Religião (NEPREL) - quando do seu início, como Mestrado, em 1993 - possuía também um caráter multidisciplinaracompanhando sua estrutura.

A trajetória em direção ao perfil que o Grupo de Pesquisa assume atualmente - passando por desmembramentos e desdobramentos - corresponde à afirmação de uma Área de Concentração no Programa, que receberáo nome de "Ciências Sociais da Religião", on de procura-se demarcar uma metodologia própria, com pesquisas empíricas de cunho qualitativo e etnográfico, ainda que em meio a uma estrutura interdisciplinar.

$\mathrm{O}$ que passamos a historiar em seguida diz respeito a uma série de fatores - de estrutura do curso, de currículo, de contratação de pessoal, de produção acadêmica de teses e dissertações - que no seu processo de transformação e aprimoramento dentro do Programa influíram decisivamente para a conformação do nosso Grupo de Pesquisa, tal qual ele se encontra hoje. 


\section{BREVE HISTÓRICO DAS ÁREAS DE CONCENTRAÇÃO, DISCIPLINAS CURRICULARES, LINHAS DE PESQUISA E PROJETOS DE PESQUISA DO PROGRAMA DE PÓS-GRADUAÇÃO EM CIÊNCIA DA RELIGIÃO (PPCIR-UFJF) NA SUA RELAÇÃO COM O GRUPO DE PESQUISA EXAMINADO}

Com a criação em 1993 do Mestrado em Ciência da Religião da UFJF e seu credenciamento na CAPES na sub-área Teologia/Ciências da Religião, o curso foi estruturado em duas grandes áreas de concentração, a saber, "Razão e Religião" e "Diálogo Inter-Religioso". A primeira, circunscrevendo abordagensmais analíticas e distanciadasda Filosofiae das Ciências Sociais, e a segunda,embora regidapela imparcialidadeacadêmica, comprometida com a promoção do diálogo inter-religioso e do ecumenismo a partir da chamada “Teologia das Religiões” (Teixeira, 1993).

Com o foco nos desdobramentos que nos interessam, na primeira área foi criada a disciplina Ciências Sociais da Religião, ao encargo do docente e sociólogo Pedro Ribeiro de Oliveira, disciplina esta que reunia tanto a abordagem sociológica quanto antropológica do fenômeno religioso. A partir de alguns anos de experi ência com esta disciplina sentiu-se necessidade no Programa de desmembrá-la em duas outras: Sociologia da religião e Antropologia da religião. Neste momento, em 1995 ingressa no Programa o antropólogo Marcelo Camurça para assumir a segunda disciplina, ficando Pedro Ribeiro com a primeira.

Em 1997, apesar do desfalque no corpo docente produzido pela aposentadoria de Pedro Ribeiro, o Programa segue empreendendo uma reformulação curricular no sentido de definir mais pormenorizadamente as ementas de suas disciplinas quando são re-elaborados os conteúdos das suas disciplinas obrigatórias e suas específicas. Na cadeirade Sociologia da Religião busca-se uma abordagem do fenômeno religioso a partir dos clássicos Durkheim, Weber e Marx e como derivação destes, teorias contemporâneas como a de Peter Berger, da secularização e "mercado dos bens simbólicos" ea de Pierre Bourdieu,do campo religioso. As cadeiras específicas Teorias Sociológicasda Religião e TópicosEspeciaisde Sociologia da Religião visamdiscutir 
temas da atualidade: religião modernidadee pós-modernidade, secularização e re-encantamento, religião e globalização,política, fundamentalismo, mídia e mercado. Ao passo que as cadeiras Antropologia da Religião e sua eletiva FundamentosTeóricos de Antropologia da Religião constituíram-se visando "relativizar", "desnaturalizar" à maneira antropológica, a religião como algo "dado", decompondo-a dentro das principa is chaves interpretativas da Antropologia, quais sejam: o mito, o rito e a magia. ${ }^{2}$ Através dessas três dimensões do modo de conhecer antropológico - elaboradas ao longo da história da Antropologia numa negociação constante da "teoria nativa" com a teoria antropológica - buscou-se apresentar as principais correntes teóricas da Antropologia (evolucionismo, culturalismo, funcionalismo, estruturalismo e interpretativismo) que se debruçaram sobre elas, cada um com seu enfoque analítico/ interpretativo. Nesse sentido, pretende-se estudar a teoria antropológica aplicada à religião, mas ela própria, religião, (des)constr uída pelo "olhar antropológico" que a interpreta.

Além dessas disciplinas, foi criada mais uma outra obrigatória, denominada Campo Religioso Brasileiro. Ela surgiu de um conteúdo que se encontrava embutido como tópico final dos programas dos cursos mais teóricosde Antropologia da Religiãoe Sociologia da Religião,correspondendo a uma parte empíricadestes cursos. Também veio a preencher uma demanda dosdiscentes (emsuas pesquisas paraas dissertações) poranálises queajudassema compreender a dinâmica que envolve as relações das religiões existentes no Brasil, entre si, assim como a posição de cada religião per si em relação à sociedade e a cultura do país. Dentro dessa perspectiva, privilegiou-se no seu conteúdo, uma visão sistematiza da das interações e relações estabeleci das entre religiões consagradas e emergentes no contexto brasileiro, verificando fenômenos de um lado, de comunicação, permuta, interpenetração, e de outro, de competição e enfrentamento entre estas; expressos através dos

2 Escapa desta classificação a penas a noção de "parentesco" também clássica na Antropologia, única não relacionada diretamente com o tema da religião (Lienhardt, 1973).

Debates do NER, Porto Alegre, ANO 8, N. 11, P. 101-118, JAN./Jun. 2007 
conceitos já consolidados como "sincretismo", "mercado de bens religiosos" e "guerra religiosa". 3

Para complementar a formação dos alunos numa visão antropológica e sociológica do fenômeno religioso, o Mestrado investe na contratação de professores visitantes de notório saber e qualificação nesta área de conhecimentos através do Programa PREVI (Programa Especial de Professores Visitantes), promovido pela admini stração central da UFJF. Em 1997, esteve lecionando aqui Otávio Velho, em 1998, Pierre Sanchis e em 1999, Regina Novaes.

Nestamesma perspectiva foramrealizados dois Seminários:o I Seminário sobre Campo Religioso Brasileiro em 1999, com as presenças dos docentes Pierre Sanchis (UFMG), Regina Novaes (UFRJ), Cecília Mariz (UERJ), Maria das Dores Campos Machado (UFRJ), Leila Amaral (Departamento de Ciências Sociais da UFJF) e Fátima Tavares (professora visitante do Mestrado), que fizeram palestras e comentaram os trabalhos e pesquisas dos mestrandos. Como parte do evento, também foi realizado o lançamento de Numen, revista de estudo e pesquisa da religião, do Mestrado e do seu Núcleo de Estudos e Pesquisa da Religião (NEPREL); e o II Semináriosobre Campo Religioso Brasileiro realizado em 2000,contando com a presença dos docentes Emerson Giumbelli(PUC-RJ), ClaraMafra(UERJ) e Pierre Sanchis (Professor Emérito da UFMG), que fizeram palestras e compuseram bancas de disser tação dos nossos discen tes que conclu íam seu Mestra do.

Em 2000, ingressa no Programa a antropóloga Fátima Tavares, tendo anteriormente, no ano de 1999, exercido aqui o cargo de professoravisitante.

\footnotetext{
${ }^{3}$ A idéia de Campo Religioso Brasileiro passou a nuclear as pesquisase projetos de dissertação em torno das disciplinas Sociologia e Antropologia da Religião, e da recém criada disciplina que tomou este nome. Como prova desta centralidade, o Projeto de Pesquisa do docente Marcelo Camurça (responsável pelo conjunto destas disciplinas) foi intitulado "Campo Religioso Brasileiro, um es paço de interações simbólicas”, sendo cadastrado na Pró-Reitoria de Pesquisa da UFJF e no NEPREL, projeto, este, "guarda-chuva" que abrigava as pes quisas de dissertações dos seus orientandos. Esta é a razão pela qual os dois Seminários organizados por este docente no Mestrado tomaram este mesmo nome (vide texto adiante).
} 
A partirde sua entrada,passa a dividiro conjunto de disciplinas acimadescrito com o docente mais antigo, responsabilizando-se pelas disciplinas do campo da "sociologia da religião" visto que o Programa onde seu doutorou lhe conferia dupla formação, em Antropologia e Sociologia. ${ }^{4}$

Em 2001, como continuidade da criação do seu Doutorado no ano de $2000,{ }^{5}$ o Programa empreende outra mudança crucial no sentido de conferir maior definiçãoe autonomia(metodológica/epistemológica) para a docência e orientação que se realizava em torno das disciplinas Antropologia e Sociologia da Religião, que foi o seu desmembramento - da Área de Razão e Religião - e a constituição de uma nova Área de Concentração, chamada "Religião, cultura e sociedade", que passa a abrigar as disciplinas Antropologia da Religião, Sociologia da Religião e Campo Religioso Brasileiro ${ }^{6}$ além de outras específicas. ${ }^{7}$

Subordinadas a esta nova Área de concentração foram criadas duas Linhas de Pesquisa: Campo Religioso Brasileiroe História Social da Religião. A diferença entre as duas linhas de pesquisa dá-se na primeira, pelo recorte sincrônico, do "presente etnográfico" do viés antropológico e da problemática da "modernidade" do viés sociológico, e na segunda pela perspectiva do "devir

${ }^{4}$ Fátima Tavares doutorou-se no ano de 1998 no Programa de Pós-Graduação em Sociologia e Antropologia Social(PPGAS) do Instituto de Filosofia e Ciências Sociais (IFCS) da UFRJ, defendendo a tese Alquimias da cura: um estudo sobre a rede terapêutica alternativa no Rio de Janeiro. No diploma do doutor habilitadopor estePrograma, consta como título o mesmoda área de seu orientador. Como a orientadora de Fátima Tavares foi ReginaNovaes, antropóloga, no diploma de Fátima, ela constou, antropóloga, embora para o Programade Ciência da Religião ela podia funcionar cobrindoa outra área de sociologia.

${ }^{5} \mathrm{O}$ curso de Doutorado possui as seguintes disciplinas obrigatórias Seminário de Doutorado e Tese de Doutorado e específicas Religião e Diálogo para a área de concentração "Diálogo Inter-Religioso", Religiões no Brasil para a área de concentração "Religião, cultura e sociedade" e Modernidade e Religião para a área de concen tração "Razão e Religião".

${ }^{6}$ Na nova grade curricular, essas três dis ciplinas passam a ser classificadas como "Gera is" eas demais, "Es pecíficas", substituindo a antig a denominação de "Obrigatórias" e "Eletivas". Para dar uma idéia do statusde cada disciplina no processo de formação do aluno, as gerais valem três créditos ao passo que as específicas podem ser de três créditos, as mais "teóricas" ou de dois, as mais temáticas.

${ }^{7}$ Foram estas as disciplinas específicas criadas ou consolidadas: História e Religião, Religiões Afro-brasileiras, Nova Consciência Religiosa,Protestantismono Brasil, Sociologiado Catolicismo Contemporâneo, Fundamentos Teóricos de Antropologiada Religĩo, TeoriasSociológicas da Religiãoe Tópicos Especiais de Sociologia da Religião.

Debates do NER, Porto Alegre, ano 8, N. 11, P. 101-118, JAn./Jun. 2007 
histórico", algo como o estudo do campo religioso brasileiro numa dimensão diacrônica. A constituição dessas Linhas com projetos de pesquiså alinhados a elas, ao encargo dos docentes ligados à nova Área de concentração se deu como consolidação de um processo de cerca de 19 dissertações de mestrado, ligadas aos temas dos projetos, concluídas no período.

Dentro do espírito dessas mudanças foi realizado em setembro de 2001 um seminário coordenado por FátimaTavarese MarceloCamurça que tomou o nome desta nova Área de concentração, "Religião, Cultura e Sociedade: experiências religiosas na contemporaneidade", com a presença de Otávio Velho (Museu Nacional - UFRJ), Carlos Alberto Afonso (Universidade de Coimbra - Portugal) e Pablo Semán (Universidad Nacional General San Martin - Argentina). Acresceu-se a isto a publicação em 2003 do livro Minas das Devoções: diversidade religiosa em Juiz de Fora, organizado pelos dois docentes da Área, com artigos seus e dos seus alunos, artigos estes, resumos e vulgatas de suas dissertações de mestrado recém defendidas.

Interessante notarque também trêscolegasteólogospertencentesà Áreade Concentração "Diálogo Inter-Religioso" do Mestrado participam colaborando com a Área "Religião, cultura e sociedade" partilhando orientações de dissertações com os seus docentes efetivos, quando a temática escolhida pelo aluno versassesobrecatolicismo, protestantismo/pentecostalismoe religiões afro-brasileiras. São eles Faustino Teixeira, Zwinglio Mota Dias e Volney Berkenbrock, pela ordem de interesse temático. Isto se deveu primeiramente ao fato de cada um delesdedicar ao estudodessas religiões uma parteconsiderável de suas trajetórias acadêmicas,constituindo-seem especialistasno tema,isto tudo facilitado pelo caráter multidisciplinar deste Programa de Ciência da Religião.

Mas numa escala mais ampla, a existência destes "teólogos adaptados" 9 às Ciências Sociais explica-se pelo uso que delas fizeram como instrumental em suas práticas nas pastorais e nos organismos ecumênicos e ONGs onde

\footnotetext{
${ }^{8}$ Projetos: Novos Movimentos Religiosos (docente responsável: Fátima Tavares), Fronteiras do Movimento Espírita em Juiz de Fora (docente responsável: Marcelo Camurça), Catolicismoe Sociedade (docente responsável: Marclo Camurça), Históriado Protestantismoe Pentecostalismo em Juiz de Fora (docnte responsável:Zwinglio Mota Dias), Religióes Afro-Brasileiras(docnte responsável: Volney Berkenbrock).

${ }^{9}$ Uma consideração sobre esta condição de teólogos voltados para as Ciências Sociais e/ou Ciências da Religião aparece em Camurça (2001a).
} 
atuavam. Tudo isso se deu em meio à influência marcante nos anos 70-80 da Sociologia, particulamenteda SociologiaMarxistana Teologia da Libertação ${ }^{10}$, que era o horizonte reflexivo onde esta geração de teólogos foi formado. Posteriormente, nos anos 90 , devido à influência da categoria "inculturação" nas novas experimentações da Teologia "engajada" nos meios populares às voltas com a crise do "parad igma marxista", este conceito derivado da Antropologia ensejava à Teologia uma outra forma de pensar a transformação da realidade, não mais no paradigma sociológico da "classe", mas na sua inserção na diversidadecultural de grupos de gênero, como mulheres, e étnicos, como indígenas e afro-descendentes. ${ }^{11}$

Também Vitória Peres de Oliveira, ${ }^{12}$ vinculada à Área de Concentração "Diálogo Inter-Religi oso", mas não da área da Teologia, com formação em Antropologia e Filosofia da Ciência, especialista nos estudos da religião Islâmica colaborou com a Área orientando dissertações sobre a inserção do Islã no campo religiosoe na sociedadebrasileira; assim como sobre a interface da religiãocom Ecologiae como derivaçãosobre as religiõesenvolvidas nestas concepções como o Santo Daime.

Além dos professores permanentesdo Programa alocados em outra Área de concentração, a Área "Religião, cultura e socied ade", contou ainda com o

${ }^{10}$ Sobre a influência do Marxismo na Teologia da Libertação, ver Camurça (2003).

${ }^{11}$ Aquestão da "inculturação" na Teologia católica "progressista" eclodiu em meio à Conferência Episcopal para América Latina (CELAM) em SantoDomingo no ano de 1990, em tornodos debates sobre o caráter do evento dos "500 anos da 'descoberta'/'dominação' (?) das Américas”. Dentre as obras de referênc ia que disseminaram esse conceito podemos citar Azevedo (1982, 1986) e Suess (1994a, 1994b).

12 Vitória Peres de Oliveira foi professora visitante do Programa nos anos 2000-2001 e posteriormente ingressou como efetiva nele no ano de 2002. Vinculada a Área de Concentração "Diálogo Inter-Religioso", depois chamada "Religiões Comparadase Perspectivas de Diálogo", dedicou-se a pesquisa e orientação no tema de estudos da Mística Islâmica coordenando um projeto com este nome e aos estudos comparados das religiões através do enfoque fenomenológico, ministrando noProgramaa cadeira de Fenomenologia da Religião.Colaborava com a Área de "Ciências Sociais da Religião", pela sua formação em Antropologia e quandosua temática tangenciava dimensõesda sociedadee cultura, requerendo umaabordagem sociológica e antropológica. Faleceu precocemente num acidente automobilístico no ano de 2006, deixando uma lacuna difícil de cobrir na sua Área e no Programa.

Debates do NER, Porto Alegre, ANo 8, N. 11, P. 101-118, JAN./Jun. 2007 
concurso - ministrando disciplinas e orientando dissertações - de docentes de outros departamentos da universidade que até então não possuíam pósgraduação. ${ }^{13}$ São eles Beatriz Domingues e Célia Borges, da História, e Raul Magalhães, das Ciências Sociais. ${ }^{14}$ Outro caso de colaboração singular com a Área foi a de Leila Amaral, antropóloga, originalmente do Departamento de Ciências Sociais, pesquisadora do fenômeno da religião na esfera da religiosidade popular em Minas Gerais e posteriormente dos novos movimentos religiosos e "Nova Era" no Brasil e no circuito internacional, com obras de referência a nível nacional (Amaral, 2000, 2003), ela colaborou inicialmente no Programa e na Área compondo bancas de dissertação. Com a sua aposentadoria em 2000, ingressa no Programa de Pós-Graduação em Ciência da Religião na condição de professora colaboradora, ministrando cursos e assumindo uma orientação. Atualmente, continua vinculada à Área e ao Núcleo de Pesquisa desenvolvendo pesquisas sobre estética, arte e o Sagrado.

Em 2003 consolida-se uma parceria com o Centro de Estudos da Religião - Pierre Sanch is (CER) da UFMG,${ }^{15}$ coordenado pela professora Léa de FreitasPerez através de sua integração e de seus alunos no Projetode Pesquisa Religião, política e cultura na juventude de Minas Gerais, cabendo a este

${ }^{13}$ O Mestrado de História da UFJF foi efetivado com credenciamento na CAPES em 2004 e o de Ciências Sociais, em 2005.

${ }^{14}$ Beatriz Domingues e Célia Borges, apesar de estarem integradas como permanentes no Mestrado em História, seguem como colaboradoras no PPCIR, agora dedicando-se principalmente a orientações, ao passo que Raul Magalhães desligou-se do nosso Programa.

${ }^{15}$ Estaparceria em estudos de juventudee religião foi conseqüência da participação de pesquisadores dos dois Núcleos em pesquisas anteriores como: "Religião, política e Ciências Sociais", coordenadapor Carlos Steil, DanielAlves e SoniaHerrera, do Núcleo de Estudos da Religião (NER) da UFRGS, que teve o seu resultado publicado em Debates do NER, onde figuramo texto de Marcelo Camurça pela UFJF (2001b) e o artigo de Lea Perez, Alexandre Cardoso e Luciana Oliveira pela UFMG(2001). As pesquisasrealizadas nos doisnúcleos no temajuventudee religião foram ainda apresentadas na IV Reunião de Antropologiado Mercosul(RAM), realizada em 2001 no Paraná, Curitiba, no Simpósio Juventud, Ciências Sociales y Religión e no Fórumde Pesquisa Religião e política entre os universitários, coordenado por Carlos Steil e

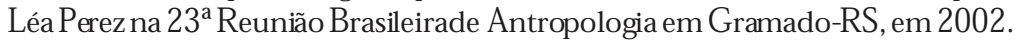


grupo a investigação na área de Belo Horizonte. Os resultados desta pesquisa foram apresentados conjuntamente em vários congressoscientíficos da área. ${ }^{16}$

Em 2004, ingressano Programa, o antropólogo Francisco Pereira Neto, ${ }^{17}$ e a partir daí a equipe com os docentes efetivos na Área de Concentração (sem contar os colegas teólogos da outra área do programa e os colaboradores de outros departamentos) estabelece o formato que ela possui atualmente. A presença de mais um docente permitiu um maior aprimoramento no conteúdo das disciplinas na direção de uma maior precisão dos métodos e técnicas de pesquisa específicas da Área, importantes para a consecução de suas Dissertaçõese Teses. Isto se deu nas cadeiras relacionadas à Antropologia da Religião que passaram além da abordagem acercadas teoriasantropológicas (aplicadas ao tema da religião) a focar a questão crucial da etnografia, modalidade pela qual a Antropologia se configura enquanto disciplina. ${ }^{18}$

A Área passou ainda a contar com a colaboração do docente Vilmar do Vale Barbosa, filósofo de formação, transferido da UFRJ para o Programa

${ }^{16}$ Os resultados da pesquisa conjunta dos Núcleos da UFJF-UFMG foram apresentados nos seguintes eventos: no Fórum de Pesquisa Juventudes: cultura e espaço urbano, religião e política coordenado por Léa Perez e Rosilene Alvim na 24ª Reunião Brasileira de Antropologia em Olinda, em 2004. Nas XIII Jornadas sobre Alternativas Religiosas na AméricaLatina no Grupo de Trabalho Juventude e religião: modulações e articulações com a cultura, socialidade e política,coordenado por Léa Perez e CarlaCoelho de Andrade em Porto Alegre, setembro de 2005. Na Mesa Redonda "Religião e Juventude: cul tura, valores moraise política", no XIICongresso Brasileirode Sociologia em BeloHorizonte, junhode 2005. Na 25ª Reunião Brasileira de Antropologia, em Goiânia, em junho de 2006, no GT "Religião em Espaços pú blicos: escolas, universidades e prisões”. Figuraram ainda em publicações como a revista Numen,vol. 07, n. 1, 2004, e na revista Ciências Socialesy Religión, n. 08, 2006.

${ }^{17}$ Doutor em AntropologiaSocialpelo PPGAS da UFRGS coma Tese Assistência Sociale Caridade: religião, política e construção da solidariedade em Porto Alegre(2001), sob a orientação de Ari PedroOro.

${ }^{18}$ Em 2006, Francisco Pereira Neto utilizaa disciplina Fundamentos Teóricos de Antropologiada Religião para ministrar um curso centrado no métodoetnográficoe seus desdobramentos: do projeto clássicomalinowskiano, passando pelo interpretativismoaté a antropologiapós-moderna, na sua relação com pesquisasantropológicas no temada religião. Em 2007, Marclo Camurça oferece na mesmadisciplina um cursosobre Etnografiae Historiografia da Religião.

Debates do NER, Porto Alegre, Ano 8, N. 11, P. 101-118, Jan./Jun. 2007 
de Pós-Graduaçãoem Ciência da Religião em 2005e alocado na Área "Diálogo inter-Religioso”. Sua participação em nossa Área cobre a temática de religião e política, na Linha de Pesquisa "Religião e Espaço Público", em que orienta e ministra cursos.

No segundo semestre de 2005 e primeiro de 2006, o Programa e a Área se beneficiaram da contratação de um professor visitante no domínio de História Social e Cultural da Religião, devido à crescente demanda pelos discentes de orientação para suas dissertações. ${ }^{19}$ A docente Patrícia Santos Schermann ${ }^{20}$ exerceu essa função no período, ministrando, dentre outros, cursos como "História e Religião", ressaltava na produção historiográfica brasileira o foco sobre a relaçãoentre Históriae religiãoevidenciandoaspectos como: controle dos corpos e subordinação à moral cristã, significados da realeza sagrada no Brasil Colônia, experiências de catolicismo vivenciadas pelas populações indígenas e negra, o olhar missionário, ritos festivos e ritos fúnebres do catolicismo. Para cumprir o período 2006 e 2007, o professor visitante Fabiano Fernandes ${ }^{21}$ ministra ocurso "História e Religião", trazendo

\footnotetext{
${ }^{19}$ Ressalta-se a significativa cifra de 14 dissertações defendidas em História social do Catolicismo e 12 em História Socialdo Protestantismo e Pentecostalismoapontadas mais adiante no balanço da produção acadêmica. Além das dissertações em curso, versando sobre variados temas do panorama das religiões no país numa perspectiva histórica: devoções populares no século XVIII, a relação da Igreja Católica com a Maçonaria no século XIX, com o divórcio no século XIX, e com a Umbanda no século XX, relações da Igreja e política a partir de 1964, pensamento católico conservador no Concílio Vaticano II, conflitos do Espiritismo com a medicina oficial no século XIX, a Nova Era e a contra-cultura nos anos 70, etc.

${ }^{20}$ Patrícia Schermann doutorou-se em História 2005 pela UFF com a Tese "Fé, Guerra e Escravidão: cristãos e muçulmanos face a Mahdiyya no Sudão (1881-1898)" orientada por Daniel Aarão Reis Filho. Em razão do seu ingresso na UFSC teve que deixar a função de professora visitante no nosso Programa. Atualmente encontra-se na UNIFESP.

${ }^{21}$ Fabiano Fernandes doutorou-se em História Social pela UFRJ no ano de 2005 com a Tese" $O$ Reino de Deus a a Espada do Rei: a formação do poder eclesiástico da Ordem de Cristonas vilas de Ega,Soure, Redinha e Pombal na primeira metade do séculoXIV', sob a orien tação de Fr ancisco José da Silva Gomes.
}

Debates do NER, Porto Alegre, ano 8, N. 11, P. 101-118, jan./Jun. 2007 
uma reflexão sobre o historiador, o seu ofício e a Nova História Religiosa e as relações entre construçãodo objeto, metodologiae a escrita historiográfica. Além das atividades de docência, os referidos professores participaram de bancas de dissertação e co-orientações de dissertações.

Verifica-se em seguida, na mesma trajetória de uma maior definição epistemológica da Área de concentração, sua mudança de nome de "Religião, cultura e sociedade" para "Ciências Sociais da Religião". A intenção foi de passar de uma nominação da Área regida pelo viés temático - embora cultura estivesse referida a antropologia e sociedade à sociologia - para uma outra, onde o referencial fosse explicitamente seu caráter epistemológico. as Ciências Sociais. ${ }^{22}$ Como conseqüência destas transformações foi criada mais uma linha de Pesquisa, intitulada "Religião e Espaço Público", que buscava acresc en tar às duas já existentes um olhar para o fenômeno religioso para além de seu lugar habitual, ontemplando processos de transversalidade desse fenômeno no âmbito do espaço público. A adoção nesta Linha de Pesquisa de uma nova perspectivada Sociologia e Antropologiaabordar o fenômeno da religião, ultrapassando os marcos de um "campo religioso", refletiu uma tendência expressa em publicações abalizadas deste campo de estudos e também dos seus congressos científicos; ${ }^{23}$ assim como de dissertações que foramdefendidas nesta Área de concentração ao longo destes últimos anos, mas que não se

\footnotetext{
${ }^{22}$ Isto foi acompanhado de um redirecionamento também nas outras Áreas de Concentração do Programa. Iniciando-se com a Área chamada de "Razão e Religião" que muda para "Filos ofia da Religião", seguida pela mudança da Área que estamos comentando e concluindo com a mudança da Área "Diálogo Inter-Religioso" para "Mística Comparada e Pers pectivas Diálogo".

${ }^{23}$ Livro Religião e Espaço Público organizado por Patrícia Birman com artigos de diversos pesquisadores, publicado pela Attar Editorial com financiamento do CNPq/Pronex em 2003. NoSeminário Temático "Republicanismo, religião e Estado no Brasil contemporâneo" coordenado por Patrícia Birman e Joanildo Burity no 28 Encontro Anual da ANPOCSem 2004. No GT "Religião em Espa ços Públicos: es colas, universidad es e pr is ões", coordenad o por Emerson Giumbelli e Maria Amélia Dickie na 25 Reunião Brasileira de Antropologia em Goiânia, em junho de 2006.
} 
encaixavam dentro do modelo de "campo religioso brasileiro" ${ }^{24}$. Em torno das três Linhas de Pesquisa atuais (Campo ReligiosoBrasileiro, História Sociale Culturalda Religiãoe Religiãoe EspaçoPúblico) gravitamuma série de projetos de pesquisa ${ }^{25}$ que nucleiam as pesquisas para a dissertação e tese dos alunos e as pesquisas dos docentes efetivos da Área cadastradas nos órgãos de fomento institucionais. ${ }^{26}$

As discussõescoletivasdessas pesquisas (em diferentesfases de andamento: projetosde pesquisa, projetos paraexamede qualificação, papers preparadospara eventos científicos, etc.) envolvendo os docentes da Área, seus orientandos e convidados constitui a atividade principal do Grupo de Pesquisa Núcleo de Estudos da Religião, Cultura e Sociedade.

Como culminância de um processo de definição epistemológica que repartiu o Programa de Pós-Graduaçãoem Ciência da Religião em três Áreas

\footnotetext{
${ }^{24}$ São exemplos desta situação as seguintes dissertações orientadas pelo docente Marcelo Camurça: Ante sala do paraíso: a sacralização do Mercadoem debate, de André Mayer, defendida em 1999; Spirituscontra Spiritum: aspectosrituaise simbólicos dos Alcólicos Anônimos, de Bernadete Pita defendida em 2001; e Cidade presépio em tempos de paixão: uma análise antropológica das relaçõesentre religião, patrimônioculturale turismo em Tiradentes, de Oswaldo Giovanninni Júnior, defendida em 2002.

${ }^{25}$ Projetos de Pesquisa ligados à Linha Campo Religioso Brasileiro. Novos Movimentos Religiosos, Religiões Afro-Brasileiras, Ethos e Identidade Espírita, Catolicismo e Sociedade e Islã e Sociedade. Vinculados à Linha de Pesquisa História Social e Cultural da Religião: História Social do Catolicismo,HistóriaSocialdas Religiões Mediúnicase História Social do Protestantismo e Pentecostalismo. Vinculados à Linha de Pesquisa Religião e Espaço Público: Cidadania, Filantropia e Religião; Saúde, Terapêutica e Religião e Modernidade, Estilo de Vida e Religião.

${ }^{26}$ O Projeto de pesquisa Religião, política e cultura na juventude de Minas Gerais, coordenado por Fátima Tavarese Marcelo Camurça, com duraçãode 2003 a 2006, contando no período com quatro bolsas de iniciação Cientifica da UFJF e do CNPq. O Projeto "Experiência Ter apêutica no âmbito do Programa de Saúde da Família em Juiz de Fora-MG”, de Fátima Tavares e Octavio Bonet, iniciado em 2006, contando com quatro bolsas de iniciação científica. O Projeto de Francisco Pereira Neto "As religiões populares na conformação do espaço público em Juiz de Fora” cadastrado em agosto de 2005 na PROPESQ e com um bolsista de iniciação científica.
}

Debates do NER, Porto Alegre, ano 8, N. 11, P. 101-118, JAN./Jun. 2007 
de concentração com suas respectivasLinhas de Pesquisa e Projetos, em 2004 o Núcleo de Estudos e Pesquisa da Religião (NEPREL) é também desdobrado em três, a saber, o Núcleo de Estudos em Filosofia da Religião(NEFR), o Núcleo de Estudos de Religião e Mística Comparada (NEMIC) e o Núcleo de Estudos em Religião, Cultura e Sociedade (NERCS), ${ }^{27}$ neste último contemplamos o balanço histórico que se segue.

Em conseqüência deste processode definições, tambéma Revista Numen pertencente ao Programa e ao antigo NEPREL, passa a ter cada um de seus fascículos sucessivamente organizados por cada uma das três Áreas e Núcleos do Programa, tendo a Área de "Ciências Sociais da Religião" e seu Núcleo já organizado o volume $7, \mathrm{n}^{0} 1$, dedicado ao tema da Juventude e Religião, e os números $8, n^{0} 1$ e $9, n^{0} 2$ que se encontram no prelo. ${ }^{28}$

\section{BREVE BALANÇO DO GRUPO DE PESQUISA NÚCLEO DE ESTUDOS EM RELIGIÃO, CULTURAE SOCIEDADE (NERCS)}

É expressivo o resultado da produção de dissertações e teses correspondentes à Área de concentração e ao Grupo de Pesquisa desde o início do Mestrado, em 1993, até o presente momento. Foram 62 dissertações de

27 ONúcleode Estudos em Religião, Cultura e Sociedade (NERCS) se encontra cadastrado no Diretório de Grupos de Pesquisa do CNPq desde seu ano de formação, em 2004, tendo como seus líderes os docentes FátimaTavares e Marcelo Camurça, e como pesquisadores os docentes Francisco Pereira Neto, Faustino Teixeira,Zwinglio MotaDias e Octavio Bonet, este último convidado, professor do Departamento de Ciências Sociais da UFJF, além de um conjunto de alunosdo Programa de Mestrado e Doutorado e bolsistas de iniciação científica, alunos da graduação.

${ }^{28}$ Numen, revista de estudos e pesquisa da religião, vol. 7, nº 1, 2004 . No prelo: os volume 08, $\mathrm{n}^{0} 1$, com artigos de Silas Guerriero (PUC-SP), Paulo Barrera Rivera (UMESP), Rogério Rosa (UFPEL) e Marjo de Theije (VU University Amsterdan). No volume 09, n 2, uma homenagem a Otávio Velho com artigos do mesmo e de Emerson Giumbelli (UFRJ), Marcelo Camurça (UFJF), Luís Eduardo Soares (IUPERJ), Leila Amaral (UFJF) e Moacir Palmeira (Museu Nacional-UFRJ). 
Mestrado e 06 teses de Doutorado, que se aplicadas (retrospectivamente) ao formato atual de divisão das Linhas de Pesquisa e Projetos, estariam assim divididas.

No Mestrado, na Linha de Pesquisa "Campo Religioso Brasileiro": 06 dissertações ligadas a "Novos Movimentos Religiosos", versando sobre grupos como Santo Daime, de Antroposofia, new agers, seus circuitos e dinâmicas, mídia "nativa" e relação espiritualidade com (para)ciências; 05 ligadas às "Religiões Afro-brasileiras", versando sobre, figuras do panteão de entidades como Exu e Pomba-Gira, comida de "santo" e relações da umbanda e candomblé; 04 ligados a "Ethos e Identidade Espírita”, contemplando temas como identidades, fronteiras e sincretismo entre kardecismo e umbanda, e cura mediúnica; 07 ligados a "Catolicismo e Sociedade", abordando segmentos e instituições do catolicismo como as CEBs, a Renovação Carismática,a Comissão Pastoralda Terra, o Conselho MissionárioIndígena e também as devoções populares e aparições marianas; 02 ligadas a "Islã e sociedade", sobre as comunidadesmuçulmanas no Brasil e relações de gênero no Islã. Na linha de Pesquisa "História Social e Cultural da Religião": 14 dissertações ligadas a "História Social do Catolicismo", abordando a presença histórica do catolicismo no Brasil em diversos períodos como, como inquisiçãono séculoXVI, relaçõesde gênero na sociedadecolonial e imperial, devoções populares à Virgem no século XVIII, Irmandades, Inconfidência Mineira, Missões em contex to de religiosidade popular, o pensamento católico conservador ultramontano, relações do Exército e a Igreja no Estado Novo, relações com a política no período da Ditadura militar, Pastora is populares, etc.; 02 ligadas a "História Social das Religiões Mediúnicas" versando sobrea gênesee transformações das religiõesafro-brasileirase espíritakardecistas em contexto de Minas Gerais; 12 ligadas a "História Social do Protestantismo e do Pentecostalismo", cobrindo os temas do fundamentalismo, da identidade pentecostal/evangélica na relação com a sociedade/ cultura brasileira, através de recortes de gênero, da política, da cidadania, do dinheiro e "Teologia da Prosperidade", e também a relação das chamadas igrejashistóricascom dimensões da sociedade nacional: metodistas e educação, luteranos e imigração,etc. Na linha de Pesquisa "Religiãoe Espaço Público", 
02 dissertações ligadas a "Cidadania, Filantropia e Religião", abordando as relações da religião com o Estado, Mercado, o Serviço Social; 01 ligada a "Saúde, Terapêutica e Religião", enfocando a questão psicológica das emoç ões e 07 ligadas a "Modernidade, estilos de vida e Religião", versando sobre as interpenetrações e atravessamentos entre religião com: música, (bio)dança, rituais laicos, Alcoólicos Anônimos, patrimônio histórico e cultural, turismo, consumo, etc.

No Doutorado, na Linha de Pesquisa "Campo Religioso Brasileiro": 02 teses ligadas a "Catolicismo e Sociedade", dedicadas ao estudo dos novos paradigmas das CPT em torno da Ecologia e a agricultura familiar e a cura interior na Renovação Carismática. Na linha de Pesquisa "História Social e Cultural da Religião": 02 teses ligadas a "História Social do Catolicismo", contemplando temáticas sobre o pensamento jesuíta no século XVII e sobre as Missões de Congregações religiosas em Minas do século XIX.

Atualmente, nos encontramos com 19 dissertaçõesde mestrado em andamento e 17 teses de doutorado na mesma situação, com defesas agendadas e previstas de 2007 a 2012.

Porfim, há que se ressaltara presençada Área e do seu Grupo de Pesquisa através dos seus docentes e alunos em eventos, simpósios, congressos referentes ao estudo científico da religião numa perspectiva sociológica, antropológica e da História social e cultural. Desde 1996, nota-se uma participação crescenteda nossa Área e Núcleo nos seguinteseventos: Jornadas sobre Alternativas Religiosas na América Latina, Simpósio da Associação Brasileirade História das Religiões(ABHR), Encontrosanuais da ANPOCS, Reunião Brasileira de Antropologia (RBA), Reunião de Antropologia do Mercosul (RAM), e Simpósio da ALER.

Muitohá ainda que aprimorar, principalmente na direção de uma maior inserção internacionaldo Programacomo um todo e da Área de concentração e seu Grupo de Pesquisa, em particular. Nesse sentido, podemos registrar as seguintes iniciativas, como o convênio firmado com a Universitá di Padova e seu Departamento de Sociologia, em particular com o grupo de pesquisa do professor Enzo Pace, docente da cadeira de Sociologia das Religiões da referida Universidade, que redundou na ida em abril de 2006 do docente 
Marcelo Camurça para apresentação de conferência "Um panorama religioso del Brasile contemporaneo" no Seminari sul pluralismo sócio-religioso nella realtá brasiliana; assim como o convênio firmado com a VU University Amsterdan, visando o intercâmbio entre professores visitantes. ${ }^{29}$

Também a entrada do nosso Grupo de Pesquisa na rede Paulo Freire Program constitui-se o mais recente movimentonesta direção que esperamos possa dar mais visibilidade as nosso trabalho e inseri-lo num circuito de maior abrangência.

\section{REFERÊNCIAS}

AMARAL, Leila. Um Espírito sem lar: sobre uma dimensão nova era da religiosidadecontemporânea. In: VELHO, Otávio (org.). Circuitos Infinitos: comparaçõese religiõesno Brasil, Argentina,Portugale França e Grã-Bretanha. São Paulo: Attar, 2003.

Carnaval da Alma. Comunidade, Essência e Sincretismo na Nova Era. Petrópolis: Vozes, 2000.

AZEVEDO, Marcello. Comunidades Eclesiais de Base e a inculturação da fé. São Paulo: Loyola, 1986

___ Inculturation and challenges of modernity. Roma:PontificalGregorian University, 1982.

CAMURÇA,Marcelo Ayres.Entre as CiênciasHumanas e a Teologia:gênese e contexto do Programa de Pós-Graduação em Ciência da Religião de Juiz de Fora em cotejo com seus congêneres no Brasil. In: GUERRIERO, Silas (org.). O Estudo das Religiões: desafios contemporâneos - Coleção de estudos ABHR. São Paulo: Paulinas, 2003, p.139-155.

\footnotetext{
${ }^{29}$ Estava previsto para o segundo semestre de 2006 a vinda da professora Marjo de Theije e a ida da docente Vitória Peres para um período de 06 meses como professoras visitantes nos dois Programas, o que foi inviabilizado pelo falecimento de VitóriaPeres.
} 
CAMURÇA, Marcelo Ayres. Ciência da Religião, Ciências da Religião, Ciências das Religiões? Observações de um antropólogo a partirda experiência no corpodocente de um Programa de Pós-Graduação da Área.In: TEIXEIRA, Faustino (org.). As Ciências da Religião no Brasil: afirmação de uma área acadêmica. São Paulo: Paulinas, 2001a, p. 201.

. Religiosidade moderna e esclarecida entre os universitários de Juiz de Fora-MG. Debates do NER, ano 2, n. 2, p. 37-64, 2001b.

LIENHARDT, Godfrey. Crença e Conhecimento. In: Antropologia Social. Rio de Janeiro: Zahar, 1973, p. 125-159.

PERES,Léa Freitas; CARDOSO, Alexandre; OLIVEIRA, Lucianade. Quem mora ao lado? $\mathrm{O}$ pecado ou a virtude? Um estudo comparativo sobre adesão religiosa e política entre estudantes de Ciências Sociais e de Comunicação da FAFICH/UFMG. Debates do NER, Porto Alegre, ano 2, n. 2, p. 37-64, 2001.

SILVA NETO, Francisco Luiz Pereira da. A Expressão Pública da Religião: estudo sobre a dinâmica do campo da Assistência Social e da Caridade em Porto Alegre. Tese (Doutorado em Antropologia Social)-PPGAS/IFCH/ UFRGS, Porto Alegre, 2001.

SUESS, Paulo. No verbo que se faz carne, o evangelho se faz cultura. Revista Eclesiástica Brasileira, Petrópolis-RJ, n. 54, fasc. 223, 1994.

Inculturação. Desafios de hoje. Petrópolis: Vozes, 1994.

TEIXEIRA, Faustino. Teologia das Religiões: uma visãopanorâmica.São Paulo: Paulinas, 1993. 